\title{
Automated identification of potential snow avalanche release areas based on digital elevation models
}

\author{
Y. Bühler ${ }^{1}$, S. Kumar ${ }^{2}$, J. Veitinger ${ }^{1,3}$, M. Christen ${ }^{1}$, A. Stoffel ${ }^{1}$, and Snehmani ${ }^{2}$ \\ ${ }^{1}$ WSL Institute for Snow and Avalanche Research SLF, Davos, Switzerland \\ ${ }^{2}$ Snow and Avalanche Study Establishment, RDC SASE, Chandigarh, India \\ ${ }^{3}$ Department of Geography, University of Zurich, Zurich, Switzerland
}

Correspondence to: Y. Bühler (buehler@slf.ch)

Received: 14 November 2012 - Published in Nat. Hazards Earth Syst. Sci. Discuss.: Revised: 21 February 2013 - Accepted: 24 April 2013 - Published: 24 May 2013

\begin{abstract}
The identification of snow avalanche release areas is a very difficult task. The release mechanism of snow avalanches depends on many different terrain, meteorological, snowpack and triggering parameters and their interactions, which are very difficult to assess. In many alpine regions such as the Indian Himalaya, nearly no information on avalanche release areas exists mainly due to the very rough and poorly accessible terrain, the vast size of the region and the lack of avalanche records. However avalanche release information is urgently required for numerical simulation of avalanche events to plan mitigation measures, for hazard mapping and to secure important roads. The Rohtang tunnel access road near Manali, Himachal Pradesh, India, is such an example. By far the most reliable way to identify avalanche release areas is using historic avalanche records and field investigations accomplished by avalanche experts in the formation zones. But both methods are not feasible for this area due to the rough terrain, its vast extent and lack of time. Therefore, we develop an operational, easyto-use automated potential release area (PRA) detection tool in Python/ArcGIS which uses high spatial resolution digital elevation models (DEMs) and forest cover information derived from airborne remote sensing instruments as input. Such instruments can acquire spatially continuous data even over inaccessible terrain and cover large areas. We validate our tool using a database of historic avalanches acquired over $56 \mathrm{yr}$ in the neighborhood of Davos, Switzerland, and apply this method for the avalanche tracks along the Rohtang tunnel access road. This tool, used by avalanche experts, delivers valuable input to identify focus areas for more-detailed
\end{abstract}

investigations on avalanche release areas in remote regions such as the Indian Himalaya and is a precondition for largescale avalanche hazard mapping.

\section{Introduction}

Avalanche release zone information such as location, extent and release height are essential for avalanche mitigation measure planning and many further topics in avalanche research. Whether an avalanche releases depends on many different coupled parameters. We can roughly classify these parameters into three groups: (a) terrain parameters such as slope, exposition, curvature, roughness and vegetation cover; (b) meteorological parameters such as wind, temperature, amount of fresh snowfall and humidity; and (c) snowpack parameters such as the existence of weak layers, the bonding between layers, free water content and grain size and grain forms (Schweizer et al., 2003). In addition, there is the triggering of the avalanche, which can be initiated by additional loading caused by humans or naturally by fresh snow or by abrupt warming (e.g. McClung and Schaerer, 2006). In this investigation, we focus on terrain parameters because they can be derived from digital elevation models (DEMs) and do not change as fast as meteorological and snowpack parameters. In many regions, these parameters are often the only ones available because no weather stations or up-to-date snow profiles are available at a reasonable distance to the area of interest. 
The idea to develop a tool to automatically derive potential avalanche release areas (PRAs) from digital terrain models is not new. The investigations of Maggioni et al. (2002), Maggioni and Gruber (2003) and Maggioni (2005) as well as the work by Ghinoi and Chung (2005) are important steps in this direction. But this research was based on DEMs with spatial resolutions coarser than $20 \mathrm{~m}$ derived by digitizing contour lines from topographic maps. Such a coarse spatial resolution of the DEM is not sufficient to capture terrain features such as smaller gullies, ridges, bumps, holes and the terrain roughness, which all are very important for avalanche formation, flow and deposition and therefore can only capture very large release zones. Two master's theses analyzed terrain features and their role for avalanche release areas for small-scale avalanches triggered by skiers and snowboarders (Vontobel, 2011) and large-scale avalanches (Bertogg, 2001). In this investigation, we refine the previous approaches for DEM datasets with higher spatial resolutions (better than $10 \mathrm{~m}$ ), include additional parameters such as surface roughness and make it operational as an easy-to-use tool for ArcGIS 10.

For the numerical simulation of snow avalanches with up-to-date tools such as RAMMS (Christen et al., 2010a; Bartelt et al., 2012a), SAMOS (Sampl and Zwinger, 2004) or ELBA+ (Keiler et al., 2006), accurate information on the location of the release area and high-quality digital elevation models are crucial (Bühler et al., 2011). They are also the base for large-scale snow avalanche hazard mapping. However, the reliable identification of release areas for different scenarios is a very difficult task. Today, avalanche experts base their release zone identification on long-term experience, field visits, and experiences from local inhabitants (Margreth et al., 2003; Rudolf-Miklau and Sauermoser, 2011) as well as on databases of historic avalanche events (e.g. Laternser et al., 1995). The more complete these datasets are, the more reliable the release zone identification gets. The most common way to map snow avalanche release areas and store them in digital databases is still to draw them by hand on topographic maps based on superimposed slope angles, field observations, and the experience of the mapping person. However, such observations are not available in most avalanche-prone areas around the world. The DEM analysis tool developed during this study aims to assist avalanche experts in building up potential avalanche release area databases. We apply this tool foremost in the remote area of Manali, Indian Himalaya (Fig. 3), where no information on past avalanche events is available.

The Survey of India (SoI) provides topographic maps at a scale of $1: 25000$ from which DEMs with $30 \mathrm{~m}$ spatial resolution can be derived. The freely available ASTER Global Digital Elevation Model (ASTER GDEM) with a spatial resolution of $30 \mathrm{~m}$ (http://gdem.ersdac.jspacesystems.or.jp/) and the Shuttle Radar Topography Mission (SRTM) with a spatial resolution of $90 \mathrm{~m}$ (Rabus et al., 2003) cover large parts of the earth surface, but beside the coarse spatial resolution, they contain numerous errors especially in high-alpine terrain (Bühler et al., 2011). DEMs with $10 \mathrm{~m}$ spatial resolution derived from CARTOSAT- 1 and -2 are also available for many areas in India but contain errors caused by clouds and cast shadow. For more-detailed terrain investigations in such complex regions we need higher spatial resolution DEMs.

We can derive high spatial resolutions DEMs (better than $5 \mathrm{~m}$ ) in high-alpine terrain from digital remote sensing imagery using digital photogrammetry techniques (e.g. Bühler et al., 2012; Kääb et al., 2005; Toutin 2004; Buchroithner, 1995). Using high-resolution satellite sensors instead of airborne sensors results in slightly worse spatial resolution and accuracy (Hobi and Ginzler, 2012). Such remote sensing instruments are more common now and are intensively applied in poorly accessible, mountainous regions to quickly gather high-quality DEM data. We need such high DEM resolution and quality for the detailed investigation of avalanche release areas. If only coarse-resolution DEM data are available, a simple classification based on slope angle will bring similar results because the additional parameters used in the algorithm (especially roughness and curvature) are not sufficiently represented in these DEM resolutions.

Therefore the main aim of the study is to develop a tool to calculate a preliminary estimate of PRA in remote areas where observations on past avalanche events are missing but high-resolution elevation models are available. The algorithm allows safety staff to obtain a first overview of where potential trigger zones are located, which can then be validated with local observations. Increasing knowledge about the specific avalanche sites allows, in a second step, the parameters used in the algorithm to be adjusted. This will enhance the performance of the latter. One example of such a remote, high-alpine area is the Rohtang tunnel access road in Manali, Indian Himalaya. This region is of specific importance because avalanches affect traffic safety of tourists, guides, rescue services and army troops in this area. Until now, very little information on avalanche activity in this area has existed. After the completion of the Rohtang tunnel project (opening planned 2015), we expect a significant increase in traffic activity during the winter months. The avalanche mitigation measures to protect this important transport link have to be planned now. To test the developed tool we use a database of recorded avalanche events from the area of Davos, Switzerland, because there is a large, accurate reference dataset available.

\section{Test sites and datasets}

\subsection{Davos, Grisons, Switzerland}

Davos is located in the Canton of Grison in the southeastern part of Switzerland (Fig. 1) and is home to the WSL Institute for Snow and Avalanche Research SLF. During the past $75 \mathrm{yr}$ many different datasets and observations on snow avalanches have been collected and many test sites in the vicinity have 


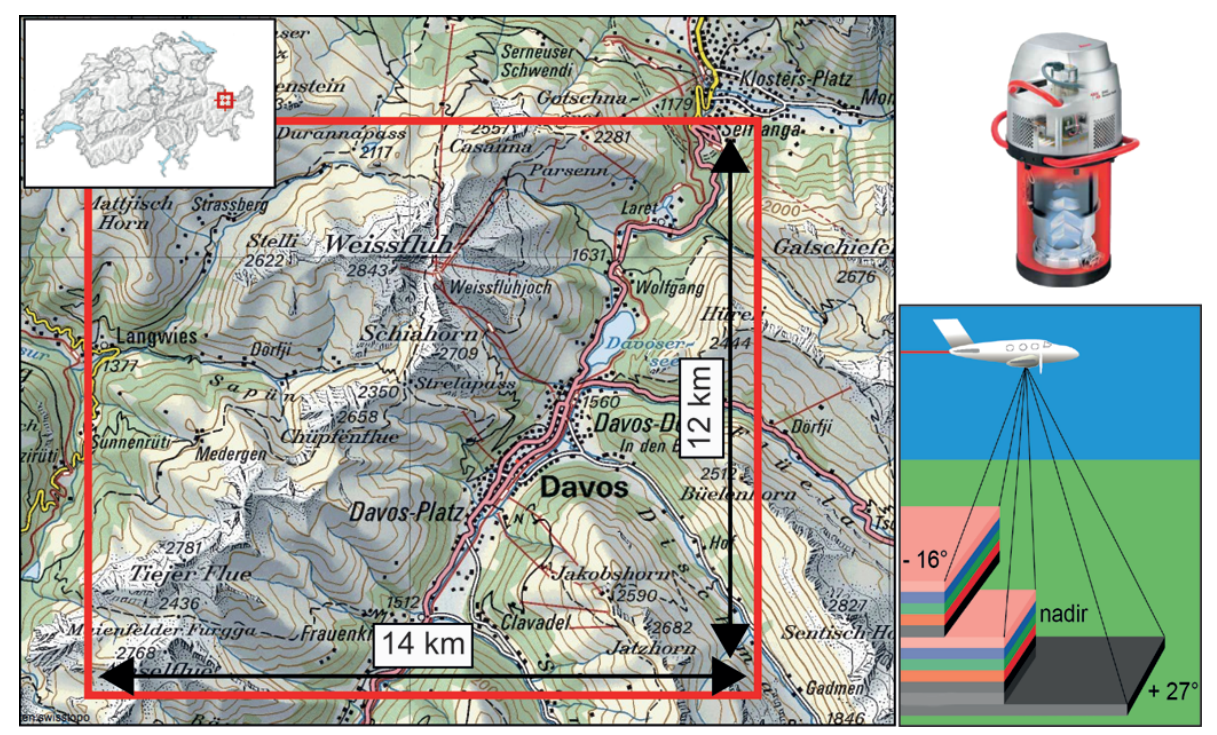

Fig. 1. Extent of the test site Davos, Switzerland (left), and images of the ADS80 digital optoelectronic scanner and its acquisition mode (right, www.leica-geosystems.com). Pixelmap (C) 2012 swisstopo (5704 000 000).

been set up. Because of this, Davos has a large number of datasets for reference purposes.

As the base for the calculation of the PRA, we use a digital surface model (DSM) derived by photogrammetric image correlation techniques based on the multispectral nadir and backward looking sensor data (digital photogrammetry). This technique has proven its ability to generate highquality and high spatial resolution digital elevation models in high-alpine terrain (Bühler et al., 2012). The original imagery is acquired by the ADS 80 optoelectronic scanner and has a spatial resolution of $0.5 \mathrm{~m}$. This sensor has already successfully been used for automated avalanche deposit detection within the same area (Bühler et al., 2009) and demonstrated the value of airborne/spaceborne remote sensing data for this purpose (Lato et al., 2012). The resulting DSM has a spatial resolution of $2 \mathrm{~m}$, four times the ground sample distance (GSD) of the input imagery as suggested by $\mathrm{Xu}$ et al. (2008). We filtered the original DSM using a $3 \times 3$ low-pass filter to get rid of artificial striping and roughness caused by image processing. The DSM covers an area of 14 by $12 \mathrm{~km}$ and reaches from the valley bottom of Davos (1500 m a.s.1.) to mountain tops with an elevation of more than 2700 m a.s.l. (Fig. 1).

To validate our automated snow avalanche release zone identification algorithm, we use a database of 4846 avalanche events of different sizes, recorded around Davos from 1956 until 2012 (Fig. 2). Observed avalanches are mapped by hand on $1: 25000$ topographic maps and then digitized as ArcGIS shapefiles. SLF and mountain safety staff mapped the recent avalanche outlines around Davos; some of them had longterm experience and very good mapping skills and others had nearly no mapping experience. However, the mapping of avalanche events from 3-D terrain on 2-D map sheets is a very difficult task and inaccuracies and mistakes occur, especially during wintertime when most terrain features are covered by snow. Only a part of all occurring avalanches during this time period has been mapped - especially in the northwestern corner of the investigation area, which is poorly accessible. Many, in particular smaller, avalanche events have been missed due to inaccessibility of the area caused by bad weather conditions or high avalanche danger. Furthermore, there is no distinction between the release, transition and deposition zone of the mapped avalanche. Despite these limitations, the completeness and accuracy of this reference dataset is unique for snow avalanche records worldwide. In the second test site, Manali, India, nearly no avalanche records are mapped at all, demonstrating the need for an automated potential avalanche release zone identification tool.

For validation purposes we identify the higher elevated third of every avalanche polygon using GIS analysis, assuming this is the release zone (Fig. 8). This is not true and not exact for most avalanche polygons; the proportion between release area and translation/deposition area may be higher for small and lower for large avalanches, but we have no exact investigations on that topic. We split the recorded avalanche events into three classes based on the total projected area: large avalanches (area $>100000 \mathrm{~m}^{2}$ ), medium avalanches (area between $100000 \mathrm{~m}^{2}$ and $50000 \mathrm{~m}^{2}$ ) and small avalanches $\left(\right.$ area $<50000 \mathrm{~m}^{2}$ ). Figure 2 gives an overview on the recorded avalanche events. Please be aware that many polygons are overlaid by other avalanche outlines. This procedure results in 197 reference release polygons for large-size avalanches, 288 for medium-size avalanches and 4361 for small-size avalanches. 


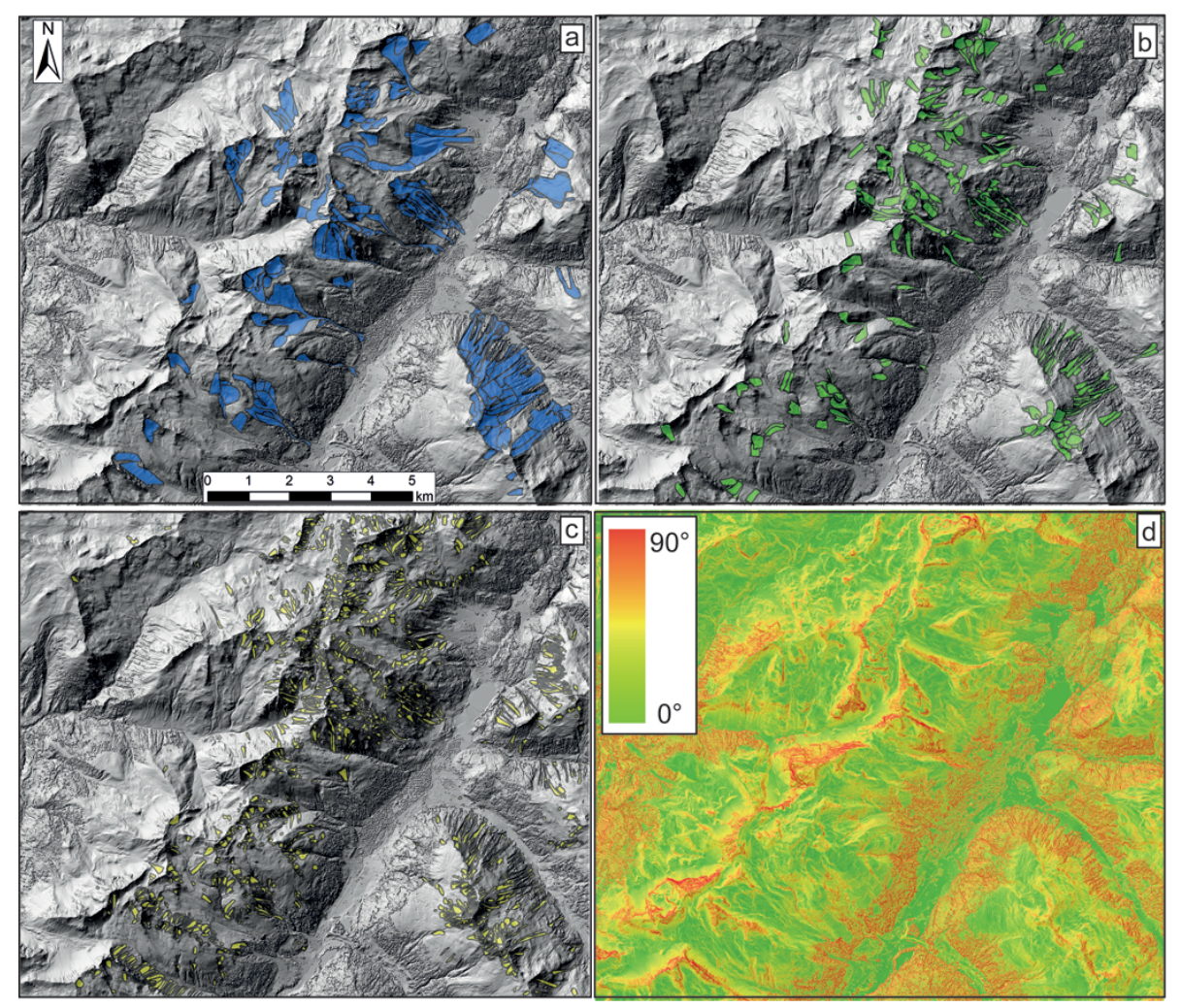

Fig. 2. Reference avalanche events used for validation of the potential avalanche release zone identification algorithm. (a) Large avalanches, $n=197$; (b) medium avalanches, $n=288$; (c) small avalanches, $n=4361$; (d) slope calculated from the summer DSM.

\subsection{Manali, Himachal Pradesh, India}

The study area Manali, a sub-basin of Beas River, lies in the Pir Panjal range in the northwestern Himalaya (Fig. 3). This area has a rapidly growing tourism sector, the ongoing infrastructure development (roads, hydropower, hotels etc.) is massive and it is an important place for national strategic reasons. The beginning of the Manali-Leh highway is threatened by a large number of avalanche tracks. The identified avalanche tracks start from MSP1 (Manali South Portal) close to Manali and continue up to MSP13, right at the entrance of the Rohtang tunnel. These avalanche tracks are located in the Kullu district. The tracks MNP1 (Manali North Portal) to MNP5 are located across the Rohtang pass in the Lahaul-Spiti district of Himachal Pradesh. This area receives a large amount of snowfall (11.5 m cumulative fresh snowfall; meteorological station Dhundi; elevation: 2870 m a.s.l.; average over two decades, 1989-2010) every winter from November to April. The average temperatures are mild (December $1.6^{\circ} \mathrm{C}$, January $-1.2{ }^{\circ} \mathrm{C}$, February $-0.4{ }^{\circ} \mathrm{C}$, March $3.1^{\circ} \mathrm{C}$, station Dhundi average over two decades, 1989-2012). As the winter progresses, we observe mainly two types of avalanche events: (a) avalanches releasing during heavy snowfall and (b) wet snow avalanches during February/March/April. Our investigation area has an extent of $126 \mathrm{~km}^{2}$ and reaches from the valley bottom of Manali (1900 m a.s.l.) to mountain tops with an elevation of more than $6000 \mathrm{~m}$ a.s.l. A large number of tourists visit the Manali area every year mainly for mountaineering and recreation activities.

In this study, we use a DSM derived from the large-format digital photogrammetry camera ULTRACAMx. This sensor was introduced in the market in 2006 (Fig. 3b). In the panchromatic band the image size is 14430 by 9420 pixels, and in the multispectral bands the image size is 4992 by 3328 pixels; the resulting ground sample distance (GSD) is dependent on the flight height over ground. The data used in this study was acquired on 7 December 2009 (Fig. 3c). The spatial resolution of the orthoimagery is approximately $0.2 \mathrm{~m}$ and the radiometric resolution is 12 bit. The spatial resolution of the derived DSM product is $1 \mathrm{~m}$. The characteristics of this DSM are very similar to the DSM used for the test site Davos.

\section{Methods}

\subsection{DEM analysis}

We base our approach on terrain parameters which can be calculated from a summer DEM and which are relevant for avalanche formation. All calculation steps are packed 

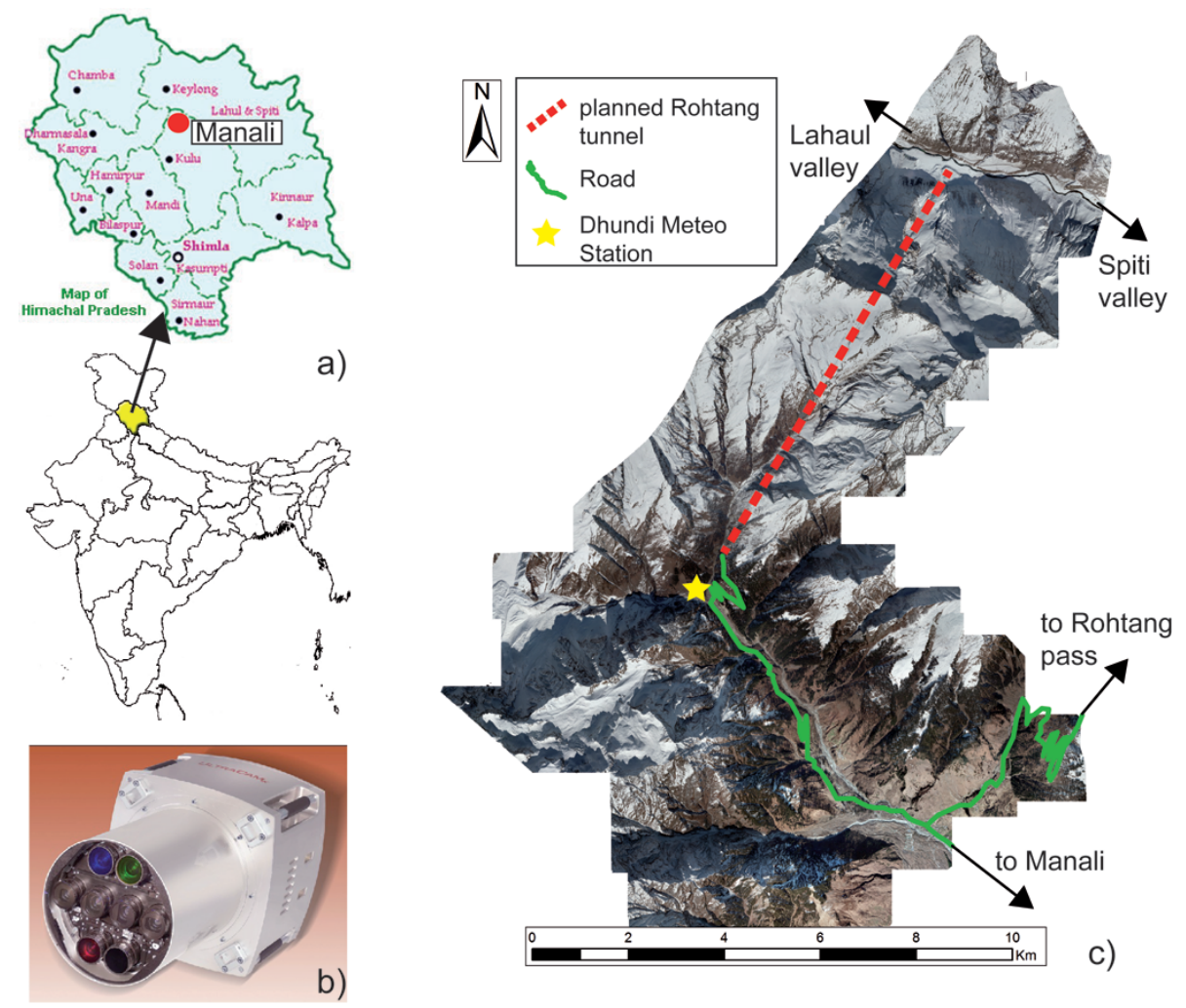

)

Fig. 3. (a) Test site Manali, Himachal Pradesh, India, (b) image of the large-format digital photogrammetry camera ULTRACAMx (Gruber et al., 2008) and (c) 7 December 2009 image of the study area.

together in a script written in Python programming language (www.python.org) that can be run as a tool in ArcGIS. To make the tool applicable in different regions, the relevant parameter thresholds can be adapted for every calculation. Here, we describe the most relevant parameters that affect the resulting release zone polygons (Fig. 4). We stress that the results of the algorithm are only potential release zones. The final plausibility checks of whether the result is plausible and avalanches can really release from the identified areas has to be done by experts based on field visits. However, this might not be possible for large, poorly accessible areas in remote regions such as Manali MSPs and MNPs.

The primary terrain parameter is slope. It is widely accepted that avalanches release from slopes between $30^{\circ}$ and $50^{\circ}$ (e.g. Schweizer et al., 2003; McClung and Schaerer, 2006). But with varying snow characteristics such as density and free water content, the threshold angles might slightly change (from $28^{\circ}$ up to $60^{\circ}$ ). Slope angles calculated from coarse-resolution DEMs might be considerably different from slope angle in the real terrain. Additionally, the snow cover reshapes the terrain and can change the slope, curvature and roughness relevant for an avalanche. The deeper the snowpack, the more significant these changes are. We calculate the slope from the summer DEM data as the maximum rate of change in value from that cell to its neighbors
(Burrough and McDonell, 1998). The slope angle parameter is implemented in the algorithm by a lower and an upper threshold value.

The second terrain parameter included is the curvature, the second derivative value of the input surface on a cell-by-cell basis (Moore et al., 1991). We identify strongly convex areas such as ridges, peaks and edges to exclude them from PRA using positive plan curvature (perpendicular to the slope direction). This approach excludes avalanche releases formed by breaking cornices. The lower the curvature threshold is set, the more convex the terrain is that is included in the PRA, resulting in release polygons reaching closer to ridge tops. The curvature is implemented in the algorithm by an upper threshold value. All regions with curvature values above this threshold will not be considered as part of potential release zones.

The third terrain parameter used in the algorithm is roughness. Roughness is believed to have a significant influence on avalanche release areas. It has been shown that a very rough and irregular surface (rocky outcrops, logs, etc.) hinders the snowpack in the downward motion (McClung, 2001). Further, rough terrain features can prevent the formation of continuous weak layers, necessary for the occurrence of large fractures in the snowpack (Schweizer et al., 2003). However, all mentioned stabilizing effects disappear if the snowpack 


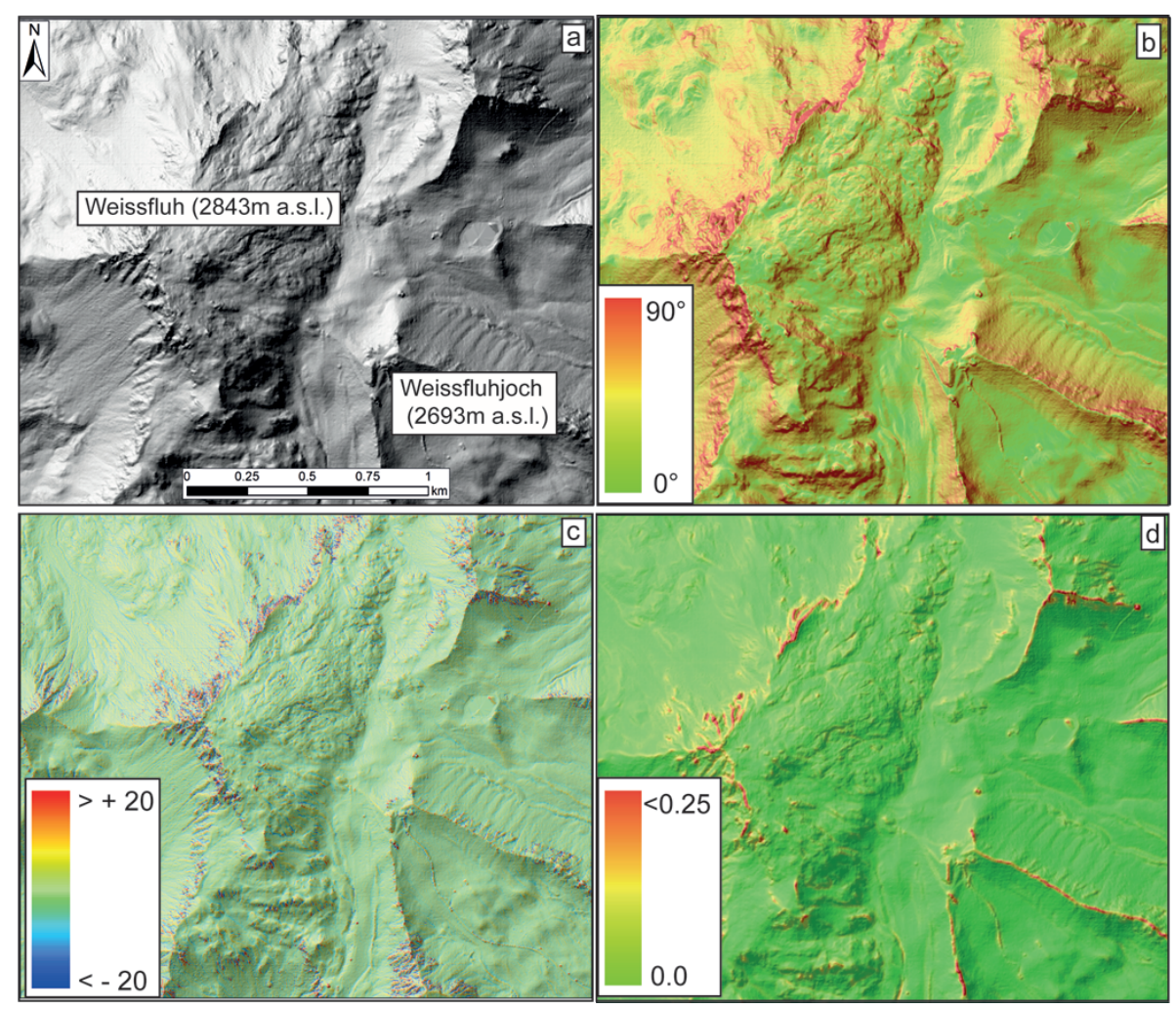

Fig. 4. (a) Hillshade and the (b) governing parameters slope, (c) plan curvature and (d) ruggedness with a neighborhood of 11 pixels considered calculated from the original DSM with a spatial resolution of $2 \mathrm{~m}$ covering the Weissfluhjoch area in Davos, Switzerland.

is deep enough to form a relatively smooth surface. Terrain roughness may then even have a destabilizing effect by adding additional stress to the snowpack and favoring snow metamorphism processes near rocks (McClung and Schaerer, 2006). Roughness is so far neglected in avalanche release area definition algorithms (Maggioni and Gruber, 2003). In the present algorithm we use the ruggedness definition of Sappington (2007). It is implemented considering the number of neighboring pixels and an upper threshold value. All regions with ruggedness values above this threshold will not be considered as part of potential release zones. Roughness and ruggedness are used synonymously in this paper.

We use the flow direction algorithm (Greenlee, 1987; Jenson and Domingue, 1988) integrated in ArcGIS to delineate between different release zones. Based on the size of the resulting polygons, we split large areas and merge or delete very small zones. The user can also adapt the minimum and maximum size of the resulting PRA before starting the calculation.

All area declared as forested in the input will be excluded from potential release zones. Furthermore, PRA which are close to forested areas and run into forests shortly after release are also excluded. We did not implement any differentiation between forest types. Therefore the decision to declare an area as forested has to be made carefully. Only dense coniferous forests keeping their needles during winter can hinder avalanche release with high enough probability. All other forest types, especially deciduous forests, should not be used in this algorithm.

\subsection{Forest classification}

Forest patch identification is a very important input influencing the formation of avalanche release areas and is also required for the numerical simulation of snow avalanches (e.g. Christen et al., 2010b). In the Davos area we include forest information from GIS layers provided by the Federal Office of Topography, swisstopo. Because such information is not available for the Manali test site, we derive forest information directly from aerial imagery. There are different methods to identify forest patches from high spatial resolution optical remote sensing data (e.g. Miller et al., 2000, Waser et al., 2008). We use the Normalized Difference Vegetation Index (NDVI; Richardson and Wiegand, 1977) because the imagery was acquired in December (winter), when deciduous trees (mainly birch trees) have no leaves and can be well distinguished from coniferous trees (pine trees). While pine trees intercept a considerable amount of the fresh falling snow hindering the formation of a larger weak layer, deciduous trees without leaves do not. For this investigation we resample the Vexcel ULTRACAMx orthoimagery (0.2 m GSD) 


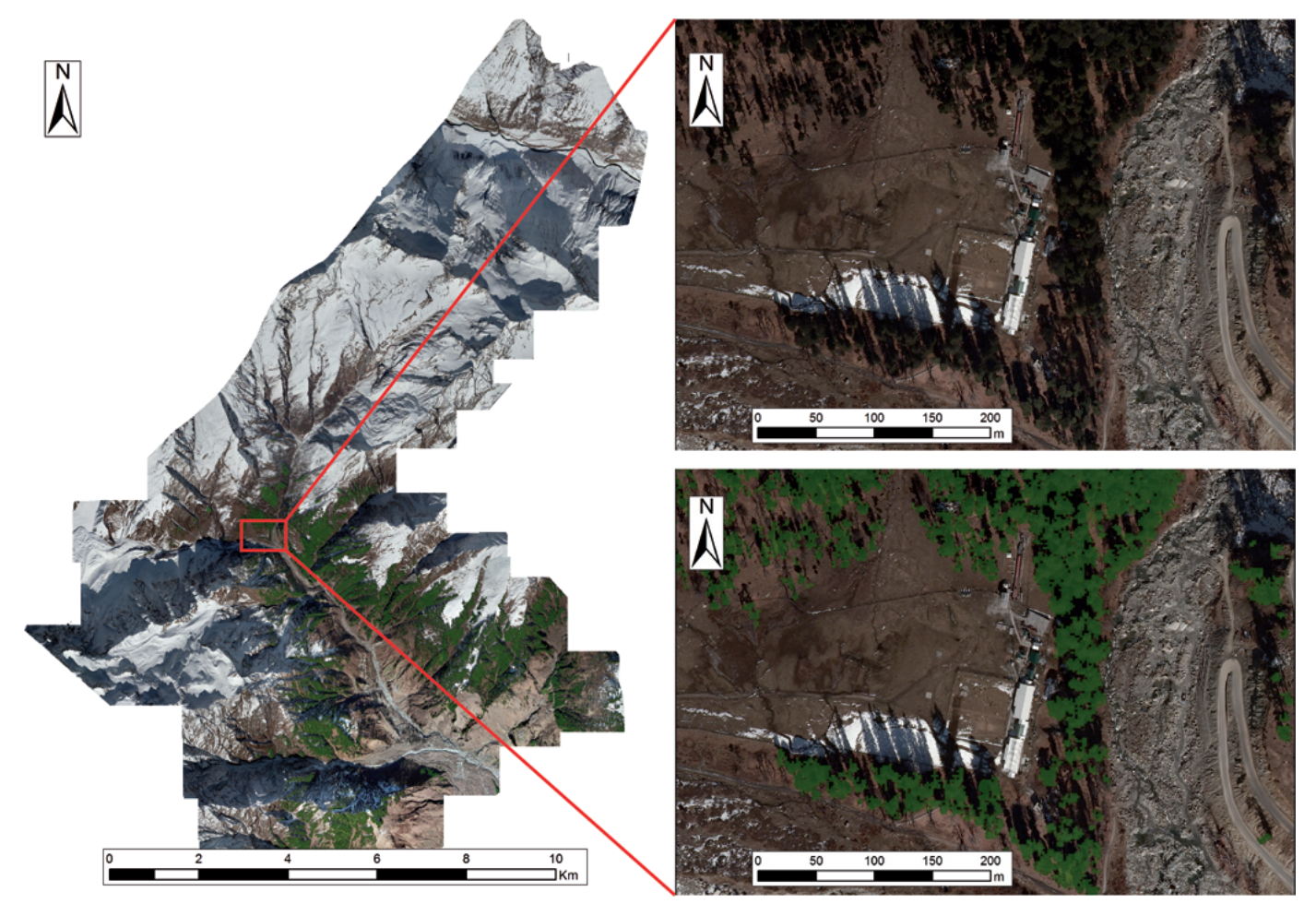

Fig. 5. (a) Results obtained for automated forest classification for the entire investigation area using supervised maximum likelihood classification with NDVI as input, (b) subset of the Dhundi Meteorological Observatory (top) and final pine tree patch classification in green (bottom).

to a spatial resolution of $2 \mathrm{~m}$. Then we calculate the NDVI using the near-infrared band (wavelength $0.68-0.91 \mu \mathrm{m}$ ) and the red band $(0.58-0.68 \mu \mathrm{m})$ and use a supervised maximum likelihood classification to identify pine tree patches relevant to snow avalanche release zones. The results are shown in Fig. 5a. To assess the quality of the automated NDVI classification we checked the results manually. We find major classification problems in areas with shadows and gullies; therefore we check these areas carefully and correct the results of the automated classification manually. For this purpose we use photographs acquired during field visits and from helicopter flight. The final result of the forest classification is shown in Fig. $5 b$.

\subsection{Algorithm accuracy estimation method}

To assess the accuracy of the algorithm we compare the results to a simple "slope approach": all pixels between $28^{\circ}$ and $50^{\circ}$ are considered as potential release area and are used for the algorithm classification (forested areas are excluded). We make the assessment for every single avalanche size class (small, medium and large) in the reference dataset. As the release zones of the reference dataset are overlapping, we simplify the geometry, uniting all avalanches of the respective size class. To assess the accuracy for the total of all avalanches, comprising all size classes, we merge all release areas of all size classes in the reference dataset. Thus, for every size class, we only distinguish between release area (PRA, when the type of avalanche occurred at least once) and no release area (NoPRA, an avalanche was never observed). Concerning the classification results of the algorithm, we neglect the partitioning into single release areas and treat them the same as the reference data (PRA or NoPRA).

The assessment is executed for the ski resort of Jakobshorn near the town of Davos. Within this area, most avalanches are documented on a regular basis by experienced ski patrollers. In all other regions, we have to assume that many avalanche events that occurred have not been mapped.

We use the following standard accuracy measures defined in Congalton and Green (1999). The overall accuracy describes the general performance of the classification and is defined as the percentage of correctly classified pixels and the total number of pixels. For this measure we include the two classes PRA and NoPRA. However, as we are mainly interested in the ability of the algorithm to classify the class PRA we use additional measures, producer's and user's accuracy. The producer's accuracy describes how well the class PRA is correctly classified. It is calculated by dividing all correctly classified pixels of the class PRA by the total of all pixels belonging to that class. It refers to the error of omission, pixels not attributed to one class although belonging to it. The users's accuracy, however, describes the reliability 
of the classification and quantifies the percentage of pixels, correctly classified as PRA over the total number of pixels classified as PRA. This measure is linked to the error of commission, pixels wrongly attributed to one class although belonging to another. To consider both factors in one measure we use the in-class accuracy. In-class accuracy is defined as the number of pixels correctly classified as PRA divided by the sum of pixels not classified as PRA but belonging to it and classified as PRA but not belonging to it. A high value of this measure indicates a good compromise between error of commission and omission.

\section{Results, validation and discussion}

\subsection{Test site Davos}

The spatial resolution of DEM data has a great impact on nearly every application using such data but especially on the presented algorithm because it is based solely on information derived directly from DEM data. Bühler et al. (2011) have already demonstrated the significant effects of DEM resolution on numerical simulations of snow avalanches. To assess these effects, we resample the original $2 \mathrm{~m}$-resolution DSM to $5 \mathrm{~m}$, $10 \mathrm{~m}, 20 \mathrm{~m}$ and $40 \mathrm{~m}$ and test the behaving of the different parameters (Fig. 6).

Because resampling always smoothes the modeled terrain, the minimum values increase and the maximum values decrease with growing pixel size (Dixon and Earls, 2009). While the minimum and maximum values change only slightly for the DEM values, the maximum slope decreases from $84.1^{\circ}(2 \mathrm{~m})$ to $58.1^{\circ}(40 \mathrm{~m})$, and also the mean slope decreases from $26^{\circ}$ to $23.3^{\circ}$ and the standard deviation from 12.6 to 10.4 . The maximum curvature decreases from $172.2(2 \mathrm{~m})$ to $5.1(40 \mathrm{~m})$, as well as the mean curvature (from 0.07 to 0.03 ) and the standard deviation (5.7 to $0.7)$. The maximum ruggedness decreases from $0.39(2 \mathrm{~m})$ to $0.19(40 \mathrm{~m})$, but the mean ruggedness increases from 0.01 to 0.04 . This is mainly due to the fact that a larger neighborhood is taken into account with lower DEM resolution (e.g. $11 \times 11$ pixel by $5 \mathrm{~m}$ DEM resolution $=55 \times 55 \mathrm{~m} ; 20 \mathrm{~m}$ DEM resolution $=220 \times 220 \mathrm{~m}$ ). This influences the results of our algorithm considerably.

Therefore, we calculate the PRA with different parameter settings for the entire test site Davos (Table 1). The different results are checked qualitatively by avalanche experts from SLF to identify a feasible parameter set for the release area identification within the test site Davos. For all calculations we use slope angle thresholds of $28^{\circ}$ and $50^{\circ}$ because these values are backed up by the literature (Schweizer et al., 2003). We fix the ruggedness threshold to $11 \times 11$ pixels because this neighborhood represents the terrain roughness assumed relevant for avalanche release. A suitable compromise between completeness (most release areas are mapped) and errors of commission (as few areas as necessary are mapped)
Table 1. Calculated parameter settings to find the optimal trade-off of mapping only as much area as necessary without missing many avalanche release zones for the test site Davos. The selected parameter set is marked in italics.

\begin{tabular}{|c|c|c|c|c|}
\hline $\begin{array}{r}\text { DEM } \\
\text { resolution }\end{array}$ & $\begin{array}{l}\text { Curvature } \\
\text { threshold }\end{array}$ & $\begin{array}{r}\text { Ruggedness } \\
\text { threshold }\end{array}$ & $\begin{array}{r}\% \text { of total } \\
\text { area between } \\
28^{\circ} \text { and } 50^{\circ}\end{array}$ & $\begin{array}{r}\text { No of } \\
\text { polygons }\end{array}$ \\
\hline $5 \mathrm{~m}$ & 0 & 0.01 & $11.25 \%$ & 1819 \\
\hline $5 \mathrm{~m}$ & 3 & 0.01 & $34.02 \%$ & 2688 \\
\hline $5 \mathrm{~m}$ & 7 & 0.01 & $34.07 \%$ & 2678 \\
\hline $5 \mathrm{~m}$ & 0 & 0.03 & $24.93 \%$ & 3746 \\
\hline $5 m$ & 3 & 0.03 & $69.53 \%$ & 4795 \\
\hline $5 \mathrm{~m}$ & 7 & 0.03 & $69.53 \%$ & 4798 \\
\hline $5 \mathrm{~m}$ & 0 & 0.05 & $29.62 \%$ & 4436 \\
\hline $5 \mathrm{~m}$ & 3 & 0.05 & $79.67 \%$ & 5573 \\
\hline $5 \mathrm{~m}$ & 7 & 0.05 & $82.10 \%$ & 5595 \\
\hline $10 \mathrm{~m}$ & 0 & 0.01 & $7.20 \%$ & 526 \\
\hline $10 \mathrm{~m}$ & 3 & 0.01 & $20.70 \%$ & 741 \\
\hline $10 \mathrm{~m}$ & 7 & 0.01 & $20.70 \%$ & 741 \\
\hline $10 \mathrm{~m}$ & 0 & 0.03 & $22.90 \%$ & 1492 \\
\hline $10 \mathrm{~m}$ & 3 & 0.03 & $59.82 \%$ & 1893 \\
\hline $10 \mathrm{~m}$ & 7 & 0.03 & $59.91 \%$ & 1893 \\
\hline $10 \mathrm{~m}$ & 0 & 0.05 & $20.70 \%$ & 741 \\
\hline $10 \mathrm{~m}$ & 3 & 0.05 & $77.30 \%$ & 2353 \\
\hline $10 \mathrm{~m}$ & 7 & 0.05 & $77.68 \%$ & 2362 \\
\hline $20 \mathrm{~m}$ & 0 & 0.01 & $2.13 \%$ & 55 \\
\hline $20 \mathrm{~m}$ & 3 & 0.01 & $9.22 \%$ & 162 \\
\hline $20 \mathrm{~m}$ & 7 & 0.01 & $9.22 \%$ & 162 \\
\hline $20 \mathrm{~m}$ & 0 & 0.03 & $14.59 \%$ & 383 \\
\hline $20 \mathrm{~m}$ & 3 & 0.03 & $45.55 \%$ & 794 \\
\hline $20 \mathrm{~m}$ & 7 & 0.03 & $45.55 \%$ & 794 \\
\hline $20 \mathrm{~m}$ & 0 & 0.05 & $22.96 \%$ & 607 \\
\hline $20 \mathrm{~m}$ & 3 & 0.05 & $68.76 \%$ & 1155 \\
\hline $20 \mathrm{~m}$ & 7 & 0.05 & $68.77 \%$ & 1155 \\
\hline
\end{tabular}

we find at a DEM resolution of $5 \mathrm{~m}$, a curvature threshold of 3 and a ruggedness threshold of 0.03 by checking the different parameter scenarios visually (Fig. 7; Table 1). We use the results calculated with this parameter settings for the validation with the 4846 release areas from the reference dataset. Lower DEM resolutions lead to the omission of many smaller- to medium-size release zones. Higher DEM resolutions lead to many very small and unrealistic release zones. Higher curvature thresholds lead to too-many and too-large release zones; lower thresholds lead to too-few and too-small zones. Higher ruggedness thresholds lead to the inclusion of very rough terrain such as rock walls or blocky scree, where an avalanche release is very unlikely. A lower ruggedness threshold would exclude too much of the steep terrain exceeding the threshold value; the winter terrain is anyway smoothed out by the snow cover compared to the summer terrain.

The results in Table 1 demonstrate how the parameters' resolution, curvature and ruggedness influence the results of the algorithm. With increasing spatial resolution, the area identified as potential release zone decreases. This is caused by missing many small-scale release areas and by decreasing the average slope angle due to terrain smoothing. Increasing 

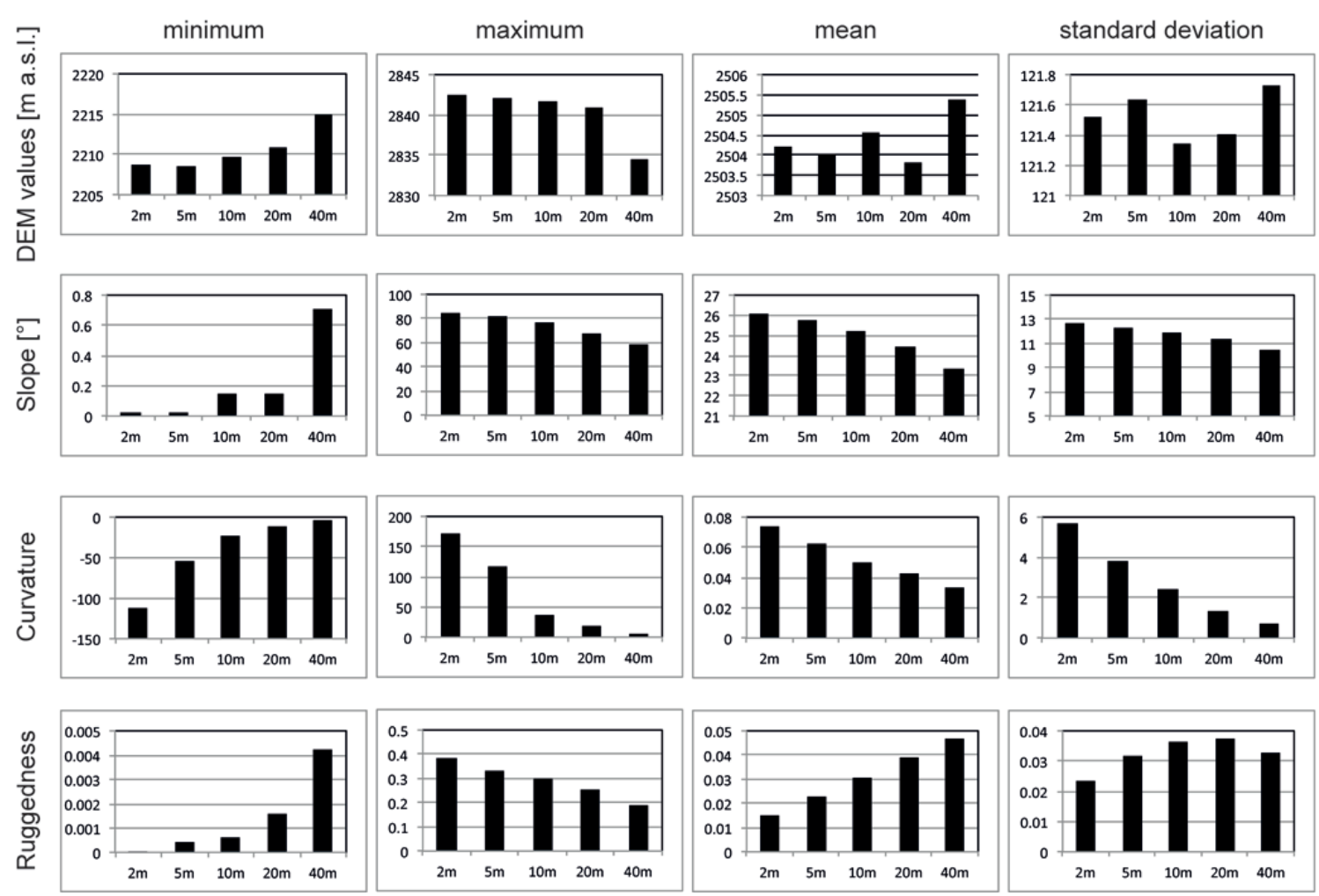

Fig. 6. Statistical comparison of the used DEM resolutions $2 \mathrm{~m}, 5 \mathrm{~m}, 10 \mathrm{~m}, 20 \mathrm{~m}$ and $40 \mathrm{~m}$ for DEM values, slope, curvature and ruggedness covering the area Weissfluhjoch pictured in Fig. 4.

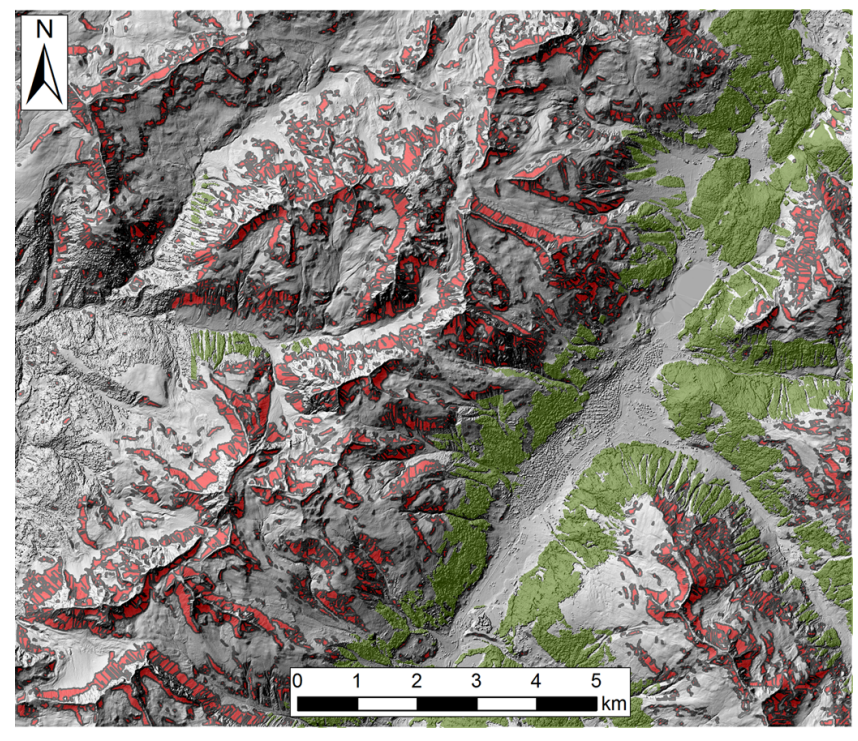

Fig. 7. Result of the automated potential avalanche release zone identification algorithm (red) for the entire investigation area Davos with a DEM resample size of $5 \mathrm{~m}$, a curvature threshold of 3 and a ruggedness threshold of 0.03 . The forest information derived from the topographic map 1:25000 is shown in green. the curvature threshold (all regions with plan curvature values bigger than the threshold value will be excluded) from 0 to 3 leads to a strong increase of the mapped release area. But increasing the value from 3 to 7 has nearly no effect. This indicates that a value of 3 is a reasonable approximation for the curvature threshold. The ruggedness threshold (all regions with ruggedness values larger than the threshold value will be excluded) has a big impact on the mapped area as well as on the number of output polygons. This indicates that the ruggedness threshold should be assessed carefully.

\subsection{Validation}

The best way to validate our algorithm would be to compare it with real avalanche release zones, which are georeferenced accurately, for example by differential Global Navigation Satellite System (dGNSS) measurements. But only very few avalanche records with accurate georeferencing exist. Therefore, we have to make some assumptions for a meaningful validation of our tool. We take the avalanche outlines of our reference dataset (see Sect. 2) and calculate the upper third of the polygon, assuming that this area will most probably contain the avalanche release zone completely (Fig. 8). However, this might not be correct for all 4846 avalanche outline polygons. In some cases, only a small part of the upper third might have released. In others it 


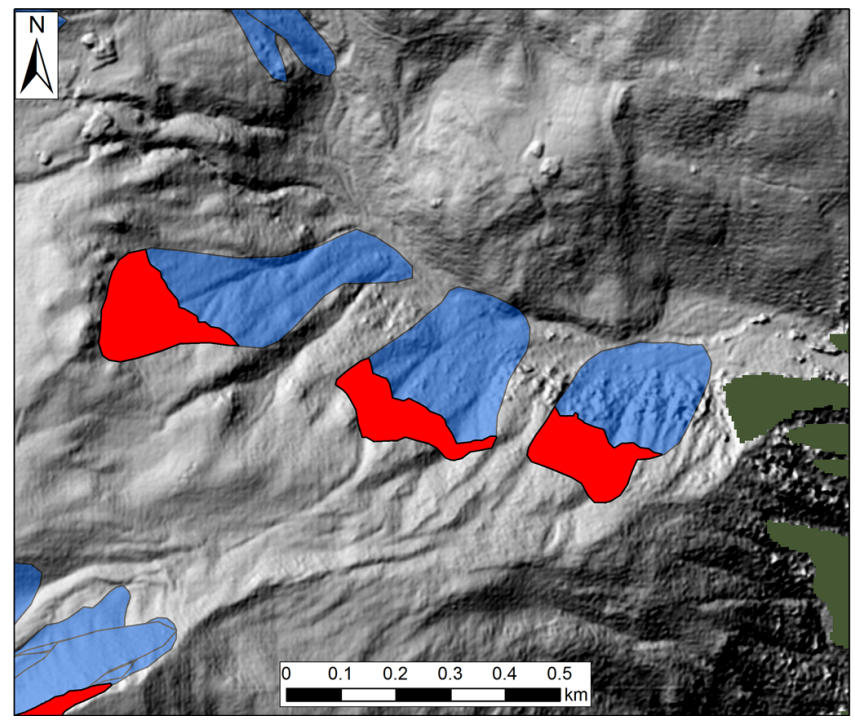

Fig. 8. Example for calculated upper thirds (red) of three avalanche polygons (blue) from the reference dataset within the test site Davos.

might be considerably more than that. But precise information is not available. Considering also the errors introduced by manual mapping, the reliability of our reference dataset is reduced considerably. But it is the best data available to verify a potential snow avalanche release zone identification algorithm.

To assess the performance of our algorithm we intersect the reference release areas (upper third of the reference avalanche outline polygons) with the area identified as potential avalanche release zone by the algorithm. For validation we use the result with a DEM resolution of $5 \mathrm{~m}$, a curvature threshold of 3 and a ruggedness threshold of 0.03 (Table 1); these are also the parameters we propose as default values for terrain characteristics comparable to the area of Davos.

For the class large avalanches $(n=197)$, only 1 reference release zone, or $0.51 \%$, does not intersect at all with the result of the algorithm; $2.4 \%$, or 4 reference release areas, are covered by less than $25 \% ; 17.7 \%$, or 35 , are covered by less than $50 \% ; 82.2 \%$ are covered by more than $50 \%$; and $47.2 \%$ are covered by more than $75 \%$ (Fig. 9). These results prove the good performance of the algorithm in detecting the release areas of large avalanches. The reference release zone not detected by the algorithm lies just above the tree line and was mapped in 1968. This area was excluded in the algorithm due to forest cover. But it is very likely that the forest has grown now in this area and an avalanche release is not probable anymore. For the class medium avalanches $(n=288)$, 3 reference release areas, or $1 \%$, are not detected by the algorithm. Twenty-four $(8.3 \%)$ are covered by less than $25 \%$; $73(25.3 \%)$ by less than $50 \%$. The algorithm covers more than $50 \%$ of 215 reference avalanche release areas $(74.7 \%)$ and more than $75 \%$ of $122(42.4 \%)$. Again the zones not

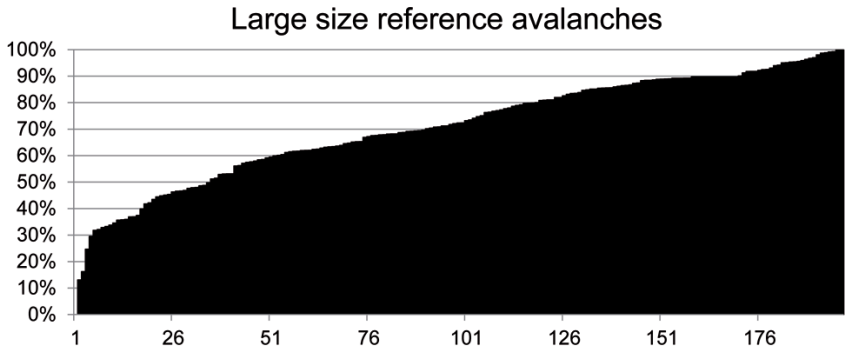

Medium size reference avalanches

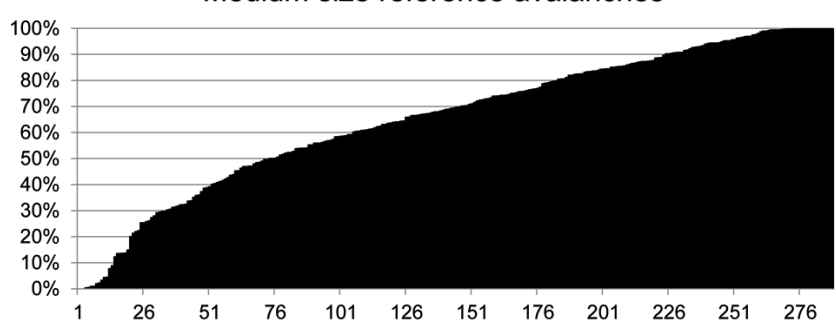

Small size reference avalanches

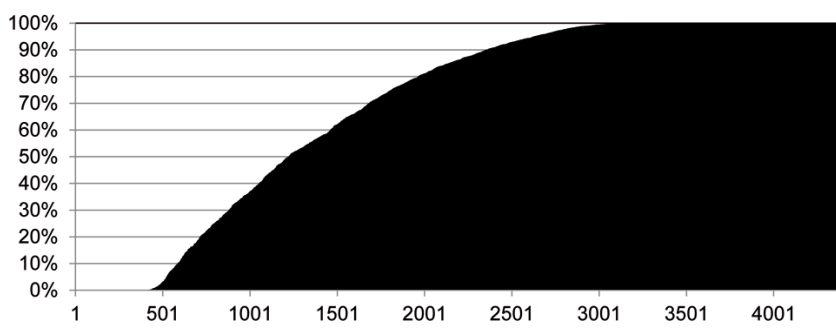

Fig. 9. Cumulative coverage of the reference release areas from the classes large $\left(>100000 \mathrm{~m}^{2}\right)$ medium (between 100000 and $\left.50000 \mathrm{~m}^{2}\right)$ and small $\left(<50000 \mathrm{~m}^{2}\right)$ by the result of the algorithm with $5 \mathrm{~m}$ DEM resolution, a curvature threshold of 3 and a ruggedness threshold of 0.03 .

identified by the algorithm are located directly above or inbetween forest-covered areas. The class small avalanches $(n=4361)$ is by far the largest but is also most corrupted by mapping errors. In this class, $422(9.7 \%)$ of the reference avalanche release areas are not detected by the algorithm; $799(18.3 \%)$ are covered by less than $25 \% ; 1222(28 \%)$ by less than $50 \% ; 3239(72 \%)$ are covered by more than $50 \%$; and $2546(58.4 \%)$ by more than $75 \%(0)$. Again a lot of the undetected release areas are located very close to forested areas. But there are also some undetected release polygons in forest-free areas. Some release areas starting very close to ridges are missed because this area was excluded by the curvature and/or the ruggedness threshold.

\subsection{Accuracy assessment}

Table 3 shows the results of the accuracy assessment. The overall accuracy increases from $39.2 \%$ to $72.8 \%$ using the algorithm, with respect to all size classes of avalanches in the reference dataset. Comparing producer's and user's accuracy for the class PRA we see that the producer's accuracy 
Table 2. Calculated parameter settings to find the optimal trade-off between mapping only as much area as necessary without missing many avalanche release zones for the test site Manali. The selected parameter set is marked in italics.

\begin{tabular}{rrrrr}
\hline $\begin{array}{r}\text { DEM } \\
\text { resolution }\end{array}$ & $\begin{array}{r}\text { Curvature } \\
\text { threshold }\end{array}$ & $\begin{array}{r}\text { Ruggedness } \\
\text { threshold }\end{array}$ & $\begin{array}{r}\% \text { of total area } \\
\text { between } 30^{\circ} \text { and } 60^{\circ}\end{array}$ & $\begin{array}{r}\text { No of } \\
\text { polygons }\end{array}$ \\
\hline $5 \mathrm{~m}$ & 0 & 0.01 & $5.80 \%$ & 1733 \\
$5 \mathrm{~m}$ & 5 & 0.01 & $18.37 \%$ & 2877 \\
$5 \mathrm{~m}$ & 7 & 0.01 & $64.06 \%$ & 7218 \\
$5 \mathrm{~m}$ & 0 & 0.03 & $17.03 \%$ & 1733 \\
$5 \mathrm{~m}$ & 5 & 0.03 & $46.98 \%$ & 5952 \\
$5 \mathrm{~m}$ & 7 & 0.03 & $47.13 \%$ & 5930 \\
$5 \mathrm{~m}$ & 0 & 0.05 & $24.19 \%$ & 6365 \\
$5 \mathrm{~m}$ & 5 & 0.05 & $62.73 \%$ & 7879 \\
$5 \mathrm{~m}$ & 7 & 0.05 & $64.42 \%$ & 7367 \\
\hline $10 \mathrm{~m}$ & 0 & 0.01 & $2.88 \%$ & 421 \\
$10 \mathrm{~m}$ & 5 & 0.01 & $10.06 \%$ & 744 \\
$10 \mathrm{~m}$ & 7 & 0.01 & $10.06 \%$ & 744 \\
$10 \mathrm{~m}$ & 0 & 0.03 & $13.38 \%$ & 1651 \\
$10 \mathrm{~m}$ & 5 & 0.03 & $35.44 \%$ & 2013 \\
$10 \mathrm{~m}$ & 7 & 0.03 & $35.44 \%$ & 2014 \\
$10 \mathrm{~m}$ & 0 & 0.05 & $21.67 \%$ & 2510 \\
$10 \mathrm{~m}$ & 5 & 0.05 & $54.25 \%$ & 2731 \\
$10 \mathrm{~m}$ & 7 & 0.05 & $54.28 \%$ & 2729 \\
\hline $20 \mathrm{~m}$ & 0 & 0.01 & $1.09 \%$ & 52 \\
$20 \mathrm{~m}$ & 5 & 0.01 & $4.29 \%$ & 131 \\
$20 \mathrm{~m}$ & 7 & 0.01 & $4.29 \%$ & 131 \\
$20 \mathrm{~m}$ & 0 & 0.03 & $6.97 \%$ & 324 \\
$20 \mathrm{~m}$ & 5 & 0.03 & $22.62 \%$ & 581 \\
$20 \mathrm{~m}$ & 7 & 0.03 & $22.62 \%$ & 581 \\
$20 \mathrm{~m}$ & 0 & 0.05 & $15.28 \%$ & 688 \\
$20 \mathrm{~m}$ & 5 & 0.05 & $42.46 \%$ & 975 \\
$20 \mathrm{~m}$ & 7 & 0.05 & $42.47 \%$ & 976 \\
\hline & & & & \\
\hline
\end{tabular}

decreases from $70.6 \%$ to $57.4 \%$; however the user's accuracy increases from $39.2 \%$ to $56.9 \%$. The algorithm identifies fewer release zones contained in the reference dataset compared to the slope approach; but the reliability of the classification is much better. The in-class accuracy is increased from $50.9 \%$ to $66.7 \%$ using the algorithm. Therefore we conclude that the algorithm provides a better compromise between errors of omission and commission and is a significant improvement over a simple slope approach. With regard to the ability of the algorithm to detect a specific size class, we see that the classification of large avalanches is more reliable than for small- and medium-sized avalanches (significantly higher user's and in-class accuracy).

The main reason for the improvement over a simple slope approach is that the algorithm contains a minimum size criterion, removing all pixels which are steep enough to be avalanche terrain but which do not form a continuous surface large enough to form an avalanche release zone (e.g. small clearings in the forest).

Although the improvement of the algorithm is significant, the classification is still far from perfect. This can partly be explained by errors in the reference dataset. As we assumed in the slope approach that avalanches can release exclusively between $28^{\circ}$ and $50^{\circ}$, all pixels of the class PRA in the reference data should be in this slope range (producer's accuracy of $100 \%$ for the slope approach). However, we observe a producer's accuracy of only $70.6 \%$. The discrepancy of around $30 \%$ can be attributed to different influences: (a) the automated definition of the release areas (upper third of the outline polygon) in the reference data is a major influence. Especially release zones of large avalanches are overestimated, thus expanding to regions flatter than $28^{\circ}$. Additionally, there might be release areas where the avalanche crown is located in terrain steeper than $28^{\circ}$, whereas the stauchwall might be significantly below $28^{\circ}$ (Bartelt et al., 2012b). However, the whole area between crown and stauchwall is defined as release zone in our study, thus also comprising areas below $28^{\circ}$. (b) Slope change caused by snow cover influences. The slope of a winter terrain can locally be very different than the underlying summer terrain. (c) The reference dataset may still lack PRAs which have not been observed or released yet but may be so in the future. Such areas have to be considered in a hazard assessment. All these factors reduce the quality of the accuracy assessment, and the value of the algorithm might be underestimated.

\subsection{Test site Manali}

The results for the entire test site Manali with a DEM resolution of $5 \mathrm{~m}$, slope inclinations from $30^{\circ}$ to $60^{\circ}$, a curvature threshold of 5 and a ruggedness threshold of 0.05 are presented in Fig. 10. The selection of the threshold values is based on expert judgment of the results from different parameter scenarios (Table 2). This is the only feasible approach because information on real avalanche release areas does not exist. Steeper slope thresholds $\left(30^{\circ}\right.$ and $\left.60^{\circ}\right)$ are used because fresh snow in the Manali area is usually moister than in Davos and the potential incoming radiation is stronger (latitude ca. $32^{\circ}$ ). This enhances the settlement of the snowpack and leads to more-stable snow covers. Therefore, significant snow accumulation can occur on steeper slope angles in the Manali region than in Europe. Because the terrain in Manali is much more rough and edged, the curvature and ruggedness thresholds are increased slightly.

A total area of $45.5 \mathrm{~km}^{2}$, or $36 \%$ of the entire area, and 6730 single release polygons are identified. This is significantly more than within the test site Davos (approx. 18\% of the entire area). Considering the much steeper terrain and fewer forest patches these results are reasonable. The algorithm excludes very rugged rock faces in the upper parts of MSP3 and MSP7 (Fig. 12). This is realistic because, in such rough terrain with many small gullies and frequent change of aspect over small distances, the formation of large-scale weak layers is unlikely. However, after very heavy snowfall in late winter, when big parts of the gullies are already filled by snow due to wind or avalanche transportation, such areas might be able to produce an avalanche release. For such situations the curvature and ruggedness parameters have to be adapted prior to the automated potential snow avalanche 
Table 3. Accuracy assessment of the algorithm and comparison with potential release areas defined only by slope angles between $28^{\circ}$ and $50^{\circ}$.

\begin{tabular}{llrr}
\hline & Size & Slope approach & Algorithm \\
& class & {$[\%]$} & {$[\%]$} \\
\hline \multirow{3}{*}{ Overall accuracy (PRA + NoPRA) } & small avalanches & 19.6 & 60.7 \\
& medium avalanches & 16.5 & 61.7 \\
& large avalanches & 27.9 & 68.1 \\
& all avalanches & 39.2 & 72.8 \\
\hline \multirow{3}{*}{ Producer's accuracy (PRA) } & small avalanches & 78.3 & 60.0 \\
& medium avalanches & 78.1 & 65.9 \\
& large avalanches & 69.3 & 58.5 \\
& all avalanches & 70.6 & 57.4 \\
\hline \multirow{3}{*}{ User's accuracy (PRA) } & small avalanches & 19.6 & 26.8 \\
& medium avalanches & 16.5 & 24.8 \\
& large avalanches & 27.9 & 41.9 \\
& all avalanches & 39.2 & 56.9 \\
\hline In-class accuracy (PRA) & small avalanches & 22.8 & 29.4 \\
& medium avalanches & 18.7 & 26.1 \\
& large avalanches & 33.0 & 68.9 \\
& all avalanches & 50.9 & 66.7 \\
\hline
\end{tabular}

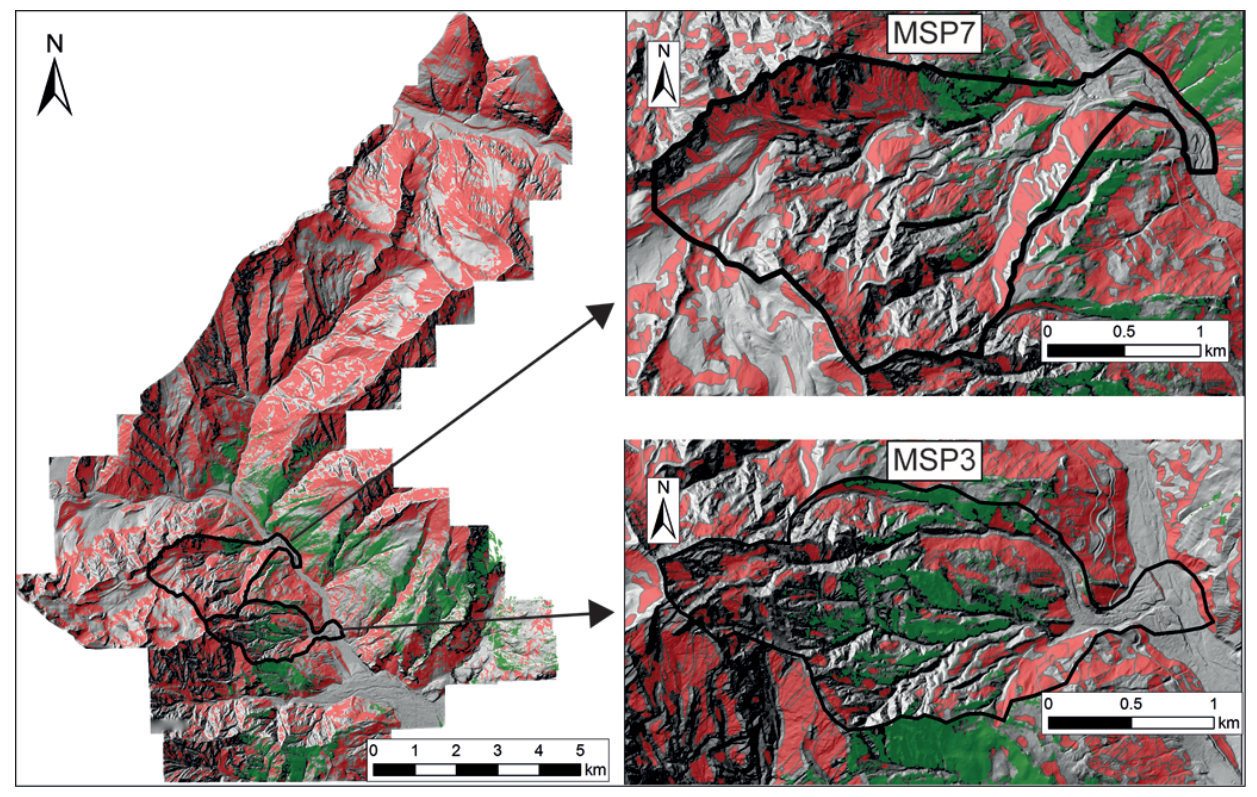

Fig. 10. The identified PRA (red) and the classified forest patches (green). A more detailed view of the results is given for the MSPs 3 and 7 (right).

release zone calculation. We presented the results of the identified PRA to SASE scientists who have already observed avalanche events in MSP 3 and 7, and they have confirmed that all release areas they know are significantly better represented by the algorithm than only by slopes between $30^{\circ}$ and $60^{\circ}$. The results are interesting for studies in the Himalaya because they enable focusing on a formerly unknown additional release areas identified by the algorithm. Future field observations and numerical avalanche simulations will show how important these newly identified release areas are for the safety of the people traveling on road. The results will also help to identify formerly unknown avalanche tracks, which are not yet part of the MSP and MNP tracks. Especially release areas in the steep flanks of the Manali range (northwestern part of the investigation area) may have the potential to generate large-scale avalanches reaching the road. 
To confirm this assumption, numerical simulations of different scenarios will have to be calculated.

\section{Conclusions}

The identification of potential avalanche release areas (PRAs) is a difficult task, but it is the precondition for largescale hazard mapping, numerical avalanche simulations and hazard mitigation measure planning. The best way to identify avalanche release areas is using snowpack information, weather data, maps, digital elevation models and photographs in combination with historic avalanche information and field investigations accomplished by experienced avalanche experts. But in many alpine areas around the world such as the Indian Himalaya, nearly no information on past avalanche events is recorded and most of the other required information is not, or only very limitedly, available. Furthermore, the dimension of the terrain affected by avalanches is vast and most regions are partly or completely inaccessible. On the other hand, high spatial resolution remote sensing sensors are able to map large areas even in otherwise inaccessible terrain. Such datasets are rapidly increasing in availability and have proven their ability to generate high-quality digital elevation model data and aerial orthoimagery (Bühler et al., 2012). For areas such as the Indian Himalaya these datasets are the only available base today for the identification of avalanche release zones.

The algorithm developed in this investigation uses digital elevation models (DEMs) and forest information derived from high spatial resolution optical remote sensing imagery to identify potential snow avalanche release zones. By only using terrain and forest information and neglecting weather and snowpack information, our approach is clearly limited and will not generate a reliable and accurate prognosis for avalanche release. Careful interpretation of the results by experts in combination with field visits is crucial. However, the tool can be used to identify potential avalanche release zones, which have to be further investigated, especially if large, poorly accessible areas have to be assessed. It is designed for large-scale hazard mapping, not for avalanche prediction. Critical parameters, which strongly influence the output, are (a) the identified forest area, (b) spatial resolution of the DEM, (c) the plan curvature and (d) the terrain ruggedness.

Because the algorithm completely excludes all forested areas and the area directly above them, no release areas will be identified there. Only dense forest stands of trees, which are able to retain a big part of the falling fresh snow, hindering the formation of a spatially continuous weak layer, should be taken into account. Deciduous trees, such as birch trees, that lose their leaves during wintertime and sparsely distributed trees should not be used to limit the potential release areas. DEMs with spatial resolutions of 2 to $10 \mathrm{~m}$ are able to identify most of the potential release zones. Higher spatial resolutions do not enable better results because the snow cover smoothes out the terrain. Lower spatial resolutions, on the other hand, are not able to capture small- to medium-size avalanche release zones. Only very big, spatially continuous release areas can be identified. Curvature values are critical for the exclusion of ridges and the separation of the different release zones. We find optimal curvature thresholds to be around three. However, if the release areas are located very close to ridges (e.g. breaking cornices) the threshold value should be increased. Very rough terrain (e.g. big rocks, narrow gullies, rockfaces) hinders the formation of large weak layers. However, large amounts of snow during winter can smooth out a big portion of the summer terrain roughness. We find suitable ruggedness threshold for the relatively smooth terrain in Davos to be approximately 0.03 and in the relatively rough terrain of Manali to be approximately 0.05 .

The validation of the algorithm using 4846 avalanche outlines from the area of Davos show that we are able to identify the major part of all occurred avalanche release zones. A qualitative and quantitative assessment of the results demonstrates that the identified PRAs are realistic and show the advantages compared to a simple slope classification. However, the delineation of the different PRAs is very difficult and depends strongly on snowpack parameters, which are ignored in this study. Therefore, the resulting PRAs have to be checked carefully and may have to be adapted prior to using them for numerical avalanche simulations or other purposes.

The results obtained for the Manali area demonstrate the value of the developed algorithm. By using this tool, the SASE scientists are able to identify specific areas of interest within a short time. Furthermore the algorithm enables first numerical simulations of different snow avalanche scenarios affecting the road, generating important parameters such as run-out distance, velocity and pressure which are needed for the planning of mitigation measures. By gathering more information on avalanche release zones during the next winters, the Indian scientists will be able to better judge the performance of the algorithm and test different parameter settings at the Manali test site. We plan to share this tool with interested avalanche experts for further testing and enhancement.

Acknowledgements. The Authors want to thank the Directors of SASE, Ashwagosha Ganju, and SLF, Jürg Schweizer, for making the exchange of their scientists possible through the close collaboration between the two institutes. We thank the Swiss National Science Foundation (SNSF) for funding the exchange of scientists through their International Short Visits program. We thank Christian Ginzler for the ADS DSM from Davos and the reviewers for their constructive suggestions.

Edited by: J. M. Vilaplana

Reviewed by: two anonymous referees 


\section{References}

Bartelt, P., Buehler, Y., Buser, O., Christen, M., and Meier, L.: Modeling mass-dependent flow regime transitions to predict the stopping and depositional behavior of snow avalanches, J. Geophys. Res.-Earth Surf., 117, doi:10.1029/2010JF001957, 2012a.

Bartelt, P., Feistl, T., Bühler, Y., and Buser, O: Overcoming the stauchwall: Viscoelastic stress redistribution and the start of full-depth gliding snow avalanches, Geophys. Res. Lett., 39, doi:10.1029/2012GL052479, 2012b.

Bertogg, R.: Analyse der Topographie von Lawinenanrissgebieten im Lawinenwinter 1999, Diplomarbeit-Universitaet Salzburg, 2001.

Buchroithner, M. F.: Problems of mountain hazard mapping using spaceborne remote sensing techniques, Adv. Space Res., 15, 5766, 1995.

Bühler, Y., Marty, M., and Ginzler, C.: High resolution DEM generation in high-alpine terrain using airborne remote sensing techniques, Trans. GIS, 6, 635-647, 2012.

Bühler, Y., Christen, M., Kowalski, J., and Bartelt, P.: Sensitivity of snow avalanche simulations to digital elevation model quality and resolution, Ann. Glaciol., 52, 72-80, 2011.

Bühler, Y., Hüni, A., Christen, M., Meister, R., and Kellenberger, T.: Automated detection and mapping of avalanche deposits using airborne optical remote sensing data, Cold Regions Sci. Technol., 57, 99-106, 2009.

Burrough, P. A. and McDonell, R. A.: Principles of Geographical Information Systems, Oxford University Press, New York, 190 pp., 1998.

Christen, M., Kowalski, J., and Bartelt, P.: RAMMS: Numerical simulation of dense snow avalanches in three-dimensional terrain, Cold Regions Sci. Technol., 63, 1-14, 2010a.

Christen, M., Bartelt, P., and Kowalski, J.: Back calculation of the In den Arelen avalanche with RAMMS: Interpretation of model results, Ann. Glaciol., 51, 161-168, 2010b.

Congalton, R. and Green, K.: Assessing the Accuracy of Remotely Sensed Data: Principles and Practices, Lewis Publishers, 1999.

Dixon, B. and Earls, J.: Resample or not?! Effects of resolution of DEMs in watershed modeling, Hydrol. Process., 23, 1714-1724, 2009.

Ghinoi, A. and Chung, C.-J.: STARTER: A statistical GIS-based model for the prediction of snow avalanche susceptibility using terrain features - Application to Alta Val Badia, Italian Dolomites, Geomorphology, 66, 305-325, 2005.

Greenlee, D. D.: Raster and Vector Processing for Scanned Linework, Photogramm. Eng. Remote Sens., 53, 1383-1387, 1987.

Gruber, M., Ponticelli, M., Bernögger, S., and Leberl, F.: ULTRACAMx, The Large Format Digital Aerial Camera System By Vexcel Imaging/Microsoft, The International Archives of the Photogrammetry, Remote Sensing and Spatial Information Sciences, Vol. XXXVII, Part B1. Beijing, 665-670, 2008.

Hobi, M. and Ginzler, C.: Accuracy assessment of digital surface models based on WorldView-2 and ADS80 stereo remote sensing data, Sensors, 12, 6347-6368, 2012.

Jenson, S. K. and Domingue, J. O.: Extracting Topographic Structure from Digital Elevation Data for Geographic Information System Analysis, Photogr. Eng. Remote Sens., 54, 1593-1600, 1988.
Kääb, A., Huggel, C., Fischer, L., Guex, S., Paul, F., Roer, I., Salzmann, N., Schlaefli, S., Schmutz, K., Schneider, D., Strozzi, T., and Weidmann, Y.: Remote sensing of glacier- and permafrostrelated hazards in high mountains: an overview, Nat. Hazards Earth Syst. Sci., 5, 527-554, doi:10.5194/nhess-5-527-2005, 2005.

Keiler, M., Sailer, R., Jörg, P., Weber, C., Fuchs, S., Zischg, A., and Sauermoser, S.: Avalanche risk assessment - a multi-temporal approach, results from Galtür, Austria, Nat. Hazards Earth Syst. Sci., 6, 637-651, doi:10.5194/nhess-6-637-2006, 2006.

Laternser, M., Lentner, S., Meister, R., Schneebeli, M., and Utelli, H.: Dokumentation zur Schadenlawinen-Datenbank (SLDB), Eidg. Institut für Schnee- und Lawinenforschung SLF, 1995.

Lato, M. J., Frauenfelder, R., and Bühler, Y.: Automated detection of snow avalanche deposits: segmentation and classification of optical remote sensing imagery, Nat. Hazards Earth Syst. Sci., 12, 2893-2906, doi:10.5194/nhess-12-2893-2012, 2012.

Maggioni, M.: Avalanche Release Areas and Their Influence on Uncertainty in Avalanche Hazard Mapping, PhD Thesis, University of Zurich UZH, 2005.

Maggioni, M., Gruber, U., and Stoffel, A.: Definition and characterisation of potential avalanche release areas, ESRI International User Conference, 1161-1166, 2002.

Maggioni, M. and Gruber, U.: The influence of topographic parameters on avalanche release dimension and frequency, Cold Regions Sci. Technol., 37, 407-419, 2003.

Margreth, S., Stoffel, L., and Wilhelm, C.: Winter opening of high alpine pass roads-analysis and case studies from the Swiss Alps, Cold Regions Sci. Technol., 37, 467-482, 2003.

McClung, D. M.: Characteristics of terrain, snow supply and forest cover for avalanche initiation caused by logging, Ann. Glaciol., 32, 223-229, 2001.

McClung, D. M. and Schaerer, P.: The Avalanche Handbook The Mountaineers Books, Seattle, 342 pp., 2006.

Miller, D., Quine, C., and Hadley, W.: An investigation of the potential of digital photogrammetry to provide measurements of forest characteristics and abiotic damage, Forest Ecol. Manage., 135, 279-288, 2000.

Moore, I. D., Grayson, R. B., and Landson, A. R.: Digital Terrain Modelling: A Review of Hydrological, Geomorphological, and Biological Applications, Hydrol. Process, 5, 3-30, 1991.

Rabus, B., Eineder, M., Roth, A., and Bamler, R.: The shuttle radar topography mission- a new class of digital elevation models acquired by spaceborne radar, Photogr. Eng. Remote Sens., 57, 241-262, 2003.

Richardson, A. J. and Wiegand, C. L.: Distinguishing vegetation from soil background information, Photogr. Eng. Remote Sens., 43, 1541-1552, 1977.

Rudolf-Miklau, F. and Sauermoser, S.: Handbuch Technischer Lawinenschutz. Berlin, Ernst and Sohn, 2011.

Sampl, P. and Zwinger, T.: Avalanche simulation with SAMOS, Ann. Glaciol., 38, 393-398, 2004.

Sappington, J. M., Longshore, K. M., and Thompson, D. B.: Quantifying Landscape Ruggedness for Animal Habitat Analysis: A Case Study Using Bighorn Sheep in the Mojave Desert, J. Wildlife Manage., 71, 1419-1426, 2007.

Schweizer, J., Jamieson, B., and Schneebeli, M.: Snow avalanche formation, Rev. Geophys., 41, 1016-1041, 2003. 
Toutin, T.: Comparison of stereo-extracted DTM from different high-resolution sensors: SPOT-5, EROS-A, IKONOS-II, and QuickBird, IEEE Trans. Geosci. Remote Sens., 42, 2121-2129, 2004.

Vontobel, I.: Geländeanalysen von Unfalllawinen, Geographisches Institut, Universität Zürich, MSc thesis. 2011.
Waser, L. T., Baltsavias, E., Ecker, K., Eisenbeiss, H., FeldmeyerChriste, E., Ginzler, C., Kuchler, M., and Zhang, L.: Assessing changes of forest area and shrub encroachment in a mire ecosystem using digital surface models and CIR aerial images, Remote Sens. Environ., 112, 1956-1968, 2008.

Xu, F., Woodhouse, N., Xu, Z., Marr, D., Yang, X., and Wang, Y.: Blunder elimination techniques in adaptive automatic terrain extraction, in: The international Archives of the Photogrammetry, Remote Sensing and Spatial Information Sciences, Bejing, China, Volume XXXVII, Comission III, 1139-1144, 2008. 